\title{
Comparison of $\mathrm{Hgb}, \mathrm{Htc}, \mathrm{Na}^{+}$, and K+ Levels Measured by Blood Gases Analyzer and Laboratory Auto-Analyzer in Different pH Stages
}

\author{
Seref Kerem Corbacioglu (D), Emine Emektar (D), Yunsur Cevik (D), Seda Dagar (D), Hikmet Sencanlar Cetiner (D), Mehmet Ali Ozbek (D), \\ Sedat Akkan (D) \\ Department of Emergency Medicine, Health Sciences University Kecioren Training and Research Hospital, Ankara, Turkey
}

Cite this article as: Corbacioglu SK, Emektar E, Cevik Y, Dagar S, Sencanlar Cetiner H, Ozbek MA, et al. Comparison of Hgb, Htc, Na+, and K+ Levels Measured by Blood Gases Analyzer and Laboratory Auto-Analyzer in Different pH Stages. Eurasian J Emerg Med. 2018 ; 17 (4): $159-64$.

\begin{abstract} Spearman's correlation test, respectively. An r-value $>0.80$ was considered a strong correlation.

\section{Introduction}

In patients who have life-threatening conditions (trauma or medical) in emergency departments (EDs) or intensive care units, to decide the appropriate management way, routine laboratory results, especially sodium $\left(\mathrm{Na}^{+}\right)$, potassium $\left(\mathrm{K}^{+}\right)$, hemoglobin $(\mathrm{Hgb})$, and hematocrit $(\mathrm{Htc})$, need to be measured quickly and reliably. However, these laboratory results are measured by a laboratory auto-analyzer (LAA) in routine practice, and this method is time consuming. Therefore, today, many physicians increasingly prefer blood gases analyzer (BGA) more in addition to routine laboratory analyses, and they decide how to manage their patients $(1,2)$.
\end{abstract}

Aim: The primary aim of the present study was to detect whether blood gases analyzer (BGA) is reliable or not in daily practice by comparing sodium ( $\mathrm{Na}^{+}$), potassium $\left(\mathrm{K}^{+}\right)$, hemoglobin $(\mathrm{Hgb})$, and hematocrit $(\mathrm{Htc})$ levels measured by BGA and laboratory auto-analyzer (LAA). The secondary aim was whether BGA is reliable or not in daily practice by comparing $\mathrm{Na}^{+}, \mathrm{K}^{+}, \mathrm{Hgb}$, and $\mathrm{Htc}$ levels measured by BGA and LAA in different $\mathrm{pH}$ stages.

Materials and methods: The study screened the electronic data and file records of all patients who were admitted to the emergency department with any complaint during the study period retrospectively. Patients who had results of venous blood gases and routine laboratory obtained at the same time were included the study. For each parameter, agreements and correlations between the results of BGA and LAA were evaluated by Bland-Altman test and

Results: The laboratory results of 1374 patients were evaluated for statistical analyses. When evaluating the correlations between the results of BGA and LAA, it was found that there was only a strong correlation for $\mathrm{K}^{+}(p<0.001, r=0.83)$. When assessing the agreements between the results of BGA and LAA, the mean differences were found to be $0.02 \pm 6.1$ for $\mathrm{Na}^{+}, 0.3 \pm 0.44$ for $\mathrm{K}^{+},-0.5 \pm 1.6$ for $\mathrm{Hgb}$, and $-0.6 \pm 5$ for $\mathrm{Htc}$.

Conclusion: Although there are strong correlation and relatively good acceptable agreement for $\mathrm{K}^{+}$measurement, there are no strong correlation and good agreement for other measurements, including $\mathrm{Na}^{+}, \mathrm{Hgb}$, and $\mathrm{Htc}$. In addition, we found that these results did not change according to the different $\mathrm{pH}$ stages.

Keywords: Blood gases analysis, venous blood gases, potassium, sodium, hemoglobin, hematocrit

Contrary to this, it is known that there are measurement differences between the results of LAA and BGA $(3,4)$. However, the results of previous studies about how reliable these differences are for use in daily practice are controversial (4-7). Therefore, we believe that further studies on this topic are needed.

The aims of the present study were to detect whether BGA is reliable or not in daily practice by comparing $\mathrm{Na}^{+}, \mathrm{K}^{+}, \mathrm{Hgb}$, and Htc levels measured by BGA and LAA and whether BGA is reliable or not in daily practice by comparing $\mathrm{Na}^{+}, \mathrm{K}^{+}, \mathrm{Hgb}$, and $\mathrm{Htc}$ levels measured by $\mathrm{BGA}$ and LAA in different $\mathrm{pH}$ stages.

ORCID IDs of the authors: SKC: 0000-0001-7802-8087; EE: 0000-0002-6056-4401; YC: 0000-0003-1325-0909; SD: 0000-0002-7874-382X; HSC: 0000-0002-9000-7059; MAO: 0000-0002-9587-2228; SA: 0000-0002-3578-9422. 


\section{Materials and Methods}

This retrospective study was conducted with patients who were admitted to the ED of a training and research hospital and who had venous blood gases (VBG) and routine laboratory results obtained at the same time between January 2016 and March 2016. The Ethics Committee of Kecioren Training and Research Hospital approved the study (Protocol ID: 102016/1222-Number: 2012KAEK-15/1222).

\section{Study population and data collection}

The present study screened the electronic data and file records of all patients who were admitted to the ED with any complaint during the study period retrospectively. Patients $>18$ years old who had results of VBG and routine laboratory obtained at the same time were included the study. Patients who lack one or more parameters in VBG or LAA, who had hemolysis in routine laboratory, who was $<18$ years old, who have treated with any intravenous transfusion before the sampling, and who did not have results of VBG and routine laboratory obtained at the same time were excluded from the study. Before the study period, three researchers, who were emergency physicians, were trained to collect data from the hospital data registration system.

For measurement of VBG, venous blood samples were obtained with heparinized syringes (PICO70 Arterial Blood Sampler; Radiometer Medical AsP, Brønshøj, Denmark) as bedside in our ED and analyzed by bedside BGA (GASTAT-1800 series pH/Blood Gas Analyzer; Techno Medica, St. Ingbert, Germany). During the study period, BGA was calibrated four times a day. The other venous blood samples, after venous blood samples were obtained, were sent to the core laboratory of the hospital for whole blood count by hematology analyzer (Abbott Cell-Dyn 3700 Hematology Analyzer; Abbott Laboratories, Abbott Park, IL, USA) and analyzing biochemistry tests by LAA using the ion-selective electrode diluted (indirect ISE) method (ARCHITECT c8000 Clinical Chemistry Analyzer-material used was 2P32 ICT sample Diluent kit; Abbott Diagnostics, Lake Forrest, IL, USA). During the study period, the core laboratory determined the calibration time as 24-hour intervals for hematology and biochemistry analyzers according to the manufacturers' instructions. Two levels of controls (normal and abnormal) were to be run every $8 \mathrm{~h}$ following calibration. The imprecision of the ICT assays for serum samples was as follows: $\mathrm{Na}^{+} 1.5 \%$ and $\mathrm{K}^{+} 2.7 \%$. All blood samples were transferred from the ED to the core laboratory using a pneumatic system in the first $30 \mathrm{~min}$. Finally, data collected from the hospital data registration system, including $\mathrm{pH}, \mathrm{Na}^{+}, \mathrm{K}^{+}, \mathrm{Hgb}$, and $\mathrm{Htc}$ values, were recorded by three researchers.

\section{Statistical analysis}

Statistical analysis were performed using Statistical Package for Social Sciences version 16.0 (SPSS Inc.; Chicago, IL, USA). The Shapiro-Wilk test was used to assess the normal distribution of all parameters. Nonparametric data were expressed as median values and interquartile range (IQR) (25\%-75\%). For each parameter $\left(\mathrm{Na}^{+}, \mathrm{K}^{+}, \mathrm{Hgb}\right.$, and $\left.\mathrm{Htc}\right)$, correlations between the results of BGA and LAA were evaluated by Spearman's correlation test. An r-value $>0.80$ was considered a strong correlation. Finally, agreements between the results of BGA and LAA were assessed by Bland-Altman test with $95 \% \mathrm{Cl}$ limits of agreement.
Table 1. Demographic and clinical characteristics of the patients

\begin{tabular}{|l|l|}
\hline Age (years), median (IQR 25\%-75\%) & $59(36-75)$ \\
\hline Sex & $584(43 \%)$ \\
\hline Male & $790(57 \%)$ \\
\hline Female & $181(13 \%)$ \\
\hline Comorbidities & $282(20 \%)$ \\
\hline Ischemic heart disease & $399(29 \%)$ \\
\hline Diabetes mellitus & $155(11 \%)$ \\
\hline Hypertension & $66(7.2 \%)$ \\
\hline Chronic obstructive pulmonary disease & $36(2.6 \%)$ \\
\hline Congestive heart failure & $40(2.9 \%)$ \\
\hline Chronic renal failure &
\end{tabular}

\section{Final diagnosis of patients}

\begin{tabular}{|l|c|}
\hline Acute abdomen & $101(7.3 \%)$ \\
\hline Acute coronary syndrome & $98(7.1 \%)$ \\
\hline Acute kidney injury & $74(5.3 \%)$ \\
\hline Soft tissue problems & $75(5.4 \%)$ \\
\hline Intoxication & $96(6.9 \%)$ \\
\hline Acute diabetes mellitus complications & $48(3.4 \%)$ \\
\hline Primer headache & $68(4.9 \%)$ \\
\hline Altered mental status & $62(4.5 \%)$ \\
\hline Peripheral vertigo & $44(3.2 \%)$ \\
\hline Syncope & $52(3.7 \%)$ \\
\hline Stroke & $78(5.6 \%)$ \\
\hline Non-specific abdominal pain & $194(14 \%)$ \\
\hline Primer epilepsy & $30(2.1 \%)$ \\
\hline Infection disease & $182(13.2 \%)$ \\
\hline Gastrointestinal hemorrhage & $34(2.4 \%)$ \\
\hline Psychiatric disorder & $17(1.2 \%)$ \\
\hline Moderate-severe trauma & $121(8.8 \%)$ \\
\hline
\end{tabular}

\section{Results}

In the study period, a total of 1562 patients who have both VBG and routine laboratory results were screened retrospectively. Of all patients, 123 who lack one or more parameters in VBG and 65 who had hemolysis in routine laboratory were excluded from the study. Finally, the laboratory results of 1374 patients were evaluated for statistical analyses. The median age of the patients was 59 (IQR 25\%-75\%: 36-75) years, and 790 (57\%) patients were female. 
Table 1 shows the demographic and clinical characteristics of the patients. Table 2 shows the results of VBG and routine laboratory of all patients.

When evaluating the correlations between the results of $B G A$ and LAA, it was found that there was a strong correlation for $\mathrm{K}^{+}$

Table 2. Venous blood gases and routine laboratory results of the patients

\begin{tabular}{|l|c|c|}
\hline & $\begin{array}{c}\text { Venous blood } \\
\text { gases }\end{array}$ & $\begin{array}{c}\text { Routine laboratory } \\
\text { results }\end{array}$ \\
\hline Sodium (mmol/L) & $137 \pm 7.1$ & $137 \pm 4.1$ \\
\hline Potassium (mmol/L) & $3.8 \pm 0.7$ & $4.2 \pm 0.6$ \\
\hline Hemoglobin (g/dL) & $13.4 \pm 2.5$ & $12.8 \pm 2.1$ \\
\hline Hematocrit $(\%)$ & $39.4 \pm 7.4$ & $38.8 \pm 5.8$ \\
\hline $\mathrm{pH}$ & $7.38 \pm 0.07$ & - \\
\hline
\end{tabular}

$(\mathrm{p}<0.001, \mathrm{r}=0.83)$, and there were moderate-high correlations for $\mathrm{Hgb}(\mathrm{p}<0.001, \mathrm{r}=0.79)$ and Htc $(\mathrm{p}<0.001, \mathrm{r}=0.78)$. In contrast, there was a poor correlation for $\mathrm{Na}^{+}(\mathrm{p}<0.001, \mathrm{r}=0.46)$ (Figure 1). However, when assessing the agreements between the results of BGA and LAA, the mean differences were found as (mean $\pm S D$ ) $0.02 \pm 6.1 \mathrm{mmol} / \mathrm{L}$ for $\mathrm{Na}^{+}, 0.3 \pm 0.44 \mathrm{mmol} / \mathrm{L}$ for $\mathrm{K}^{+},-0.5 \pm 1.6 \mathrm{~g} / \mathrm{dL}$ for $\mathrm{Hgb}$, and $-0.6 \pm 5 \%$ for Htc. After Bland-Altman analyses, it was found that although there was a relatively good acceptable agreement for $\mathrm{K}^{+}$measurements, there was a poor agreement for $\mathrm{Na}^{+}, \mathrm{Hgb}$, and $\mathrm{Htc}$ measurements for clinical use (Figure 2).

In addition, in the present study, agreements between values of VBG and routine laboratory were evaluated in different $\mathrm{pH}$ stages. Overall, 835 patients had normal pH range (7.35-7.45), 336 had acidosis (<7.35), and 203 had alkalosis (>7.45). Similar to the results of the analysis in which all samples were included, after BlandAltman analysis in different $\mathrm{pH}$ stages, it was found that there was a relatively good acceptable agreement for $\mathrm{K}^{+}$measurement, and there was a poor agreement for $\mathrm{Na}^{+}, \mathrm{Hgb}$, and $\mathrm{Htc}$ measurements (Table 3).
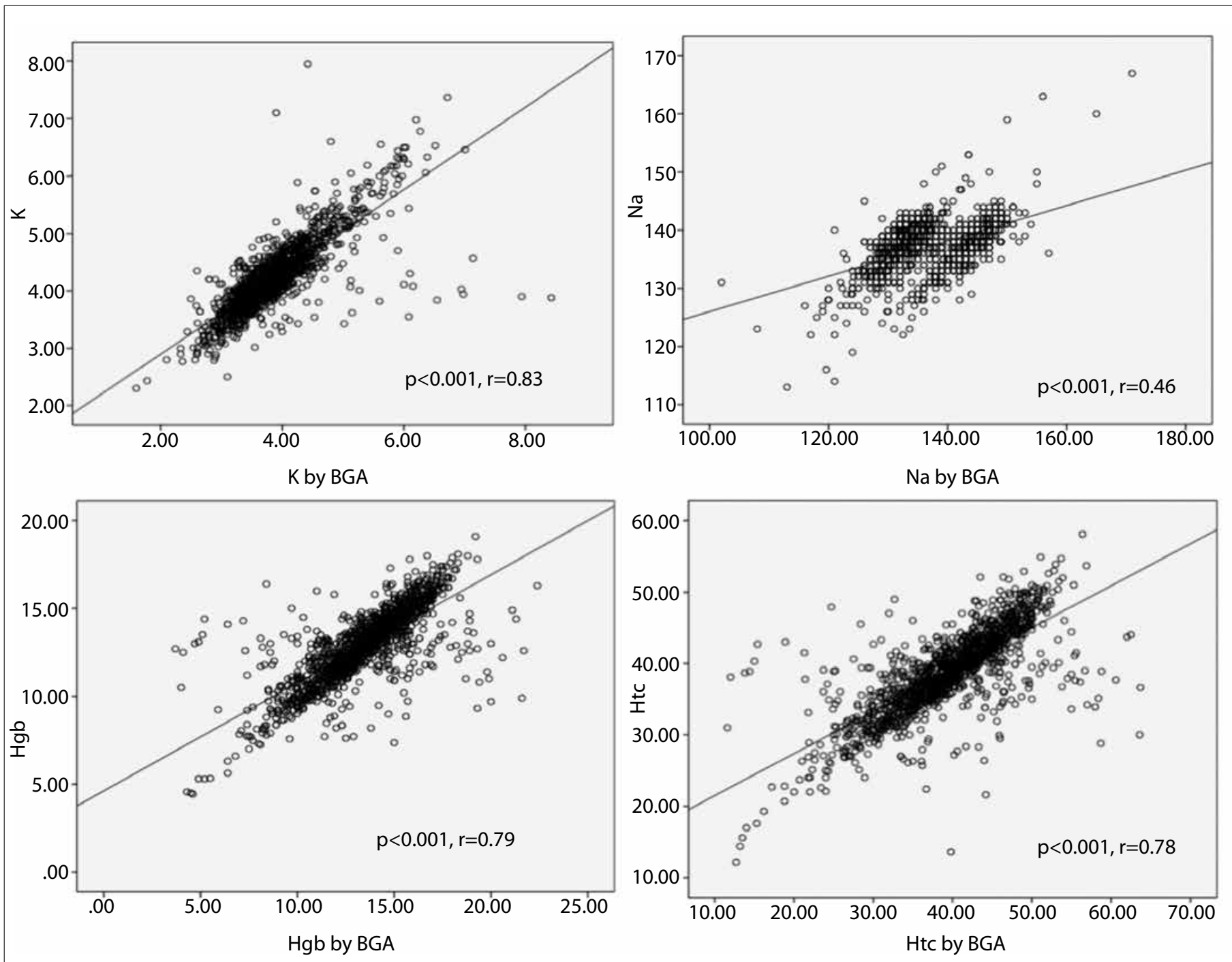

Figure 1. Scatter plots for the four parameters $\left(\mathrm{Na}^{+}, \mathrm{K}^{+}, \mathrm{Hgb}\right.$, and $\left.\mathrm{Htc}\right)$ studied. BGA: blood gases analyzer 


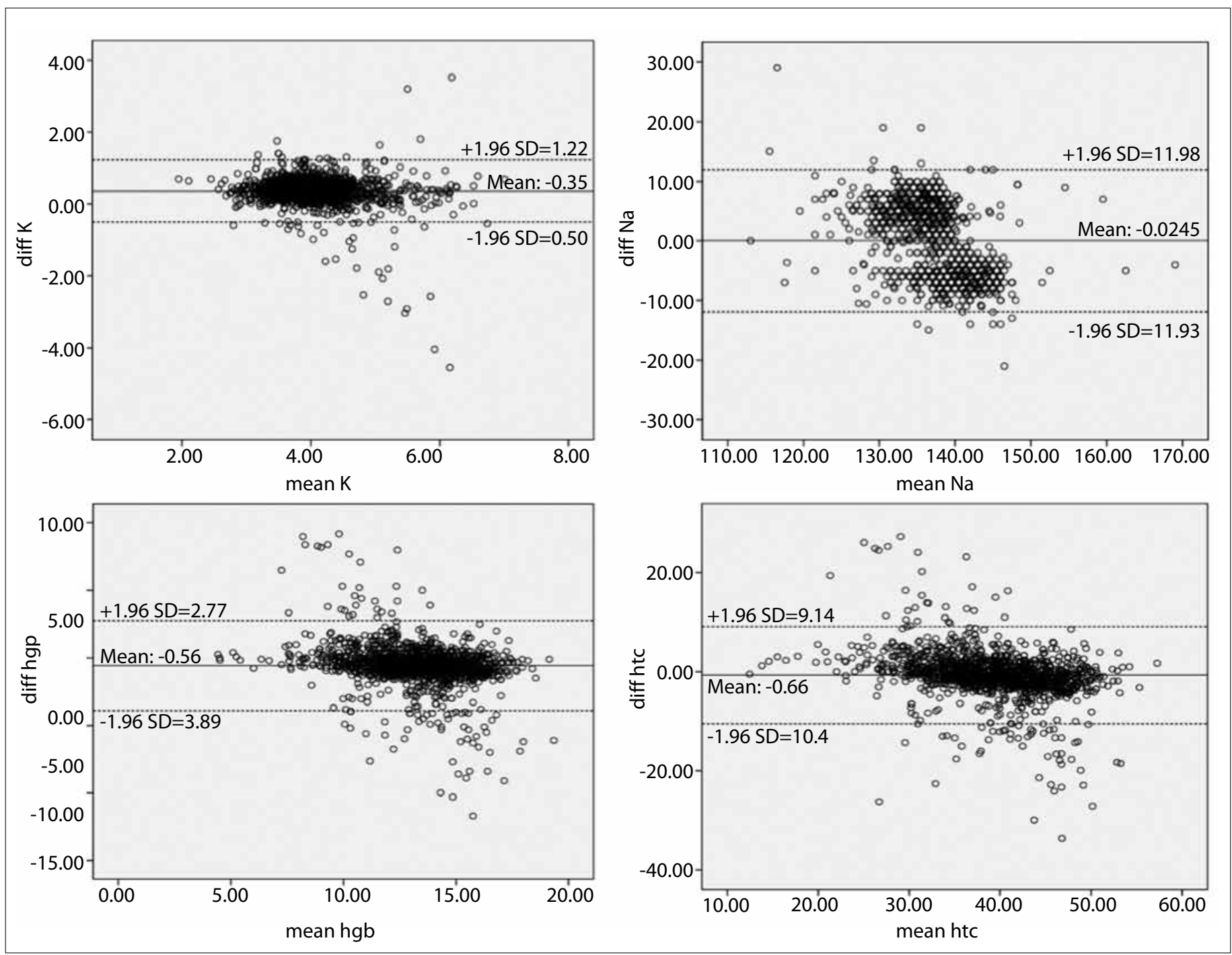

Figure 2. Agreement limits of $\mathrm{K}^{+}, \mathrm{Na}^{+}, \mathrm{Hgb}$, and $\mathrm{Htc}$ variables according to the Bland-Altman analysis. Flat lines showed the mean differences of measurements by blood gases analyzer and laboratory auto-analyzer; dotted lines showed agreements limited with $95 \% \mathrm{Cl}$

\section{Discussion}

The results of the present study showed that in measurements by BGA and LAA, although there are strong correlation and relatively good acceptable agreement for $\mathrm{K}^{+}$measurement, there are no strong correlation and good agreement for other measurements, including $\mathrm{Na}^{+}, \mathrm{Hgb}$, and Htc. In addition, we found that these results did not change according to the different $\mathrm{pH}$ stages.

\section{$\mathrm{K}^{+}$and $\mathrm{Na}^{+}$measurements}

It is known that quick and reliable measurements of $\mathrm{K}^{+}$and $\mathrm{Na}^{+}$are crucial in non-traumatic medical critical illness. For example, early detection of hypernatremia or hyponatremia in patients with acute altered mental status can be life-saving. Similarly, early detection of hypokalemia or especially hyperkalemia can be crucial for decision of hemodialysis and prevention of life-threatening ventricular dysrhythmia (8-9). In the present study, we found that there is no strong correlation for $\mathrm{Na}^{+}$between BGA and LAA. In addition, when evaluating the agreement limits for $\mathrm{Na}^{+}$, we found quite a wide range of agreement limits as -11.9 to 11.9 . We believe that this wide range is not acceptable for daily practice in the ED. In the litarature there are some studies, which had similar results with our study's results. For example, in Solak's study conducted on 2257 patients, evaluation of the agreements of $\mathrm{Na}^{+}$results was measured by BGA and biochemistry auto-analyzer (BAA) in different stages of $\mathrm{Na}^{+}$level, including hyponatremia, eunatremia, and hypernatremia. In addition, it has been reported that there are poor correlation and significant differences of measurements between LAA and BAA (10). In another study, which evaluated the agreements of $\mathrm{Na}^{+}$and $\mathrm{K}^{+}$results as measured by LAA and BGA, conducted by Budak et al. (11) with 1105 test samples, it was found that a wide range of agreement limits (mean diff: 4.94, LoA: -0.97 to 10.85 ) for $\mathrm{Na}^{+}$is similar to our result. In contrast to the results of these studies, in two different studies conducted by Zhang et al. (12) and Uysal et al. (5), they have found narrower agreement limits for $\mathrm{Na}^{+}$measurements (mean diff: 3.0, LoA: -1.2 to 7.3 and mean diff: -1.63 , LoA: -6.63 to 3.37 , respectively). Of course, interpretation of results by Bland-Altman is very subjective and can be changed in different clinical scenarios. However, we believe that even in the study that has the best agreement limit values, these values were distributed over relatively wide range. Therefore, we 
Table 3. Mean and mean difference of $\mathrm{Na}+, \mathrm{K}+, \mathrm{Hgb}$, and $\mathrm{Htc}$ levels in VBG and routine laboratory with agreement limits according to the Bland-Altman analyses

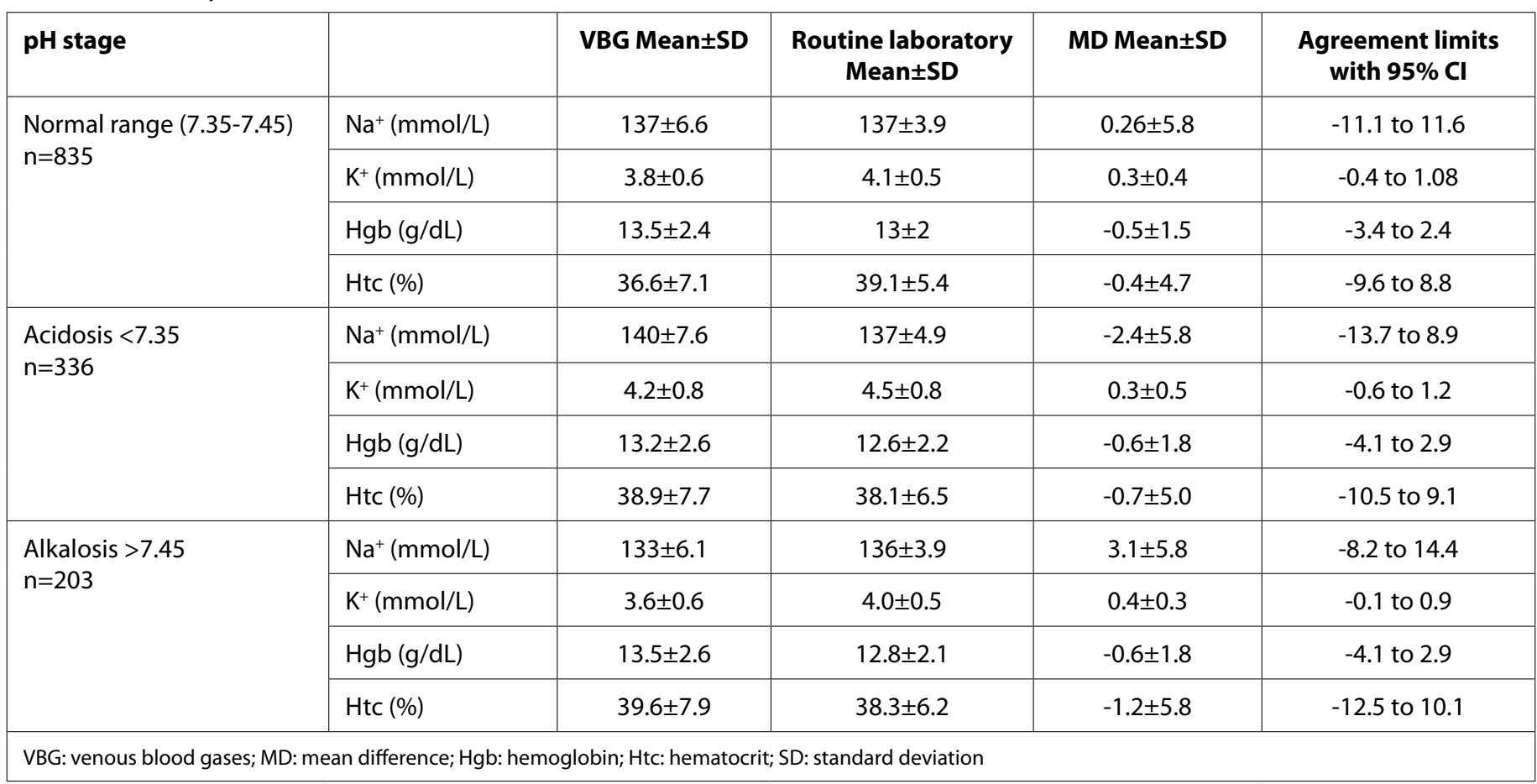

believe that $\mathrm{Na}^{+}$results measured by BGA are not reliable enough for use in the ED practice, and physicians should be aware of the risk of bias in using $\mathrm{BGA}$ for $\mathrm{Na}^{+}$measurements.

In contrast to $\mathrm{Na}^{+}$measurements, we found that there is a strong correlation for $\mathrm{K}^{+}$between BGA and LAA. In addition, when evaluating the agreement limits for $\mathrm{K}^{+}$, we found a relatively good acceptable agreement (-0.5 to 1.22). In the literature, there are studies that have similar findings to our findings for $\mathrm{K}^{+}$. However, these similar results were discussed with different perspectives by the authors of these studies. For example, in the study conducted by Uysal et al. (5) with 1094 patients, they aim to investigate the correlation and agreement of some results measured by BGA and core laboratory analyzer. They reported that there are strong correlation $(r=0.82)$ and good acceptable agreement for $\mathrm{K}^{+}$measurements (mean: -0.46 , LoA: -1.34 to 0.42 ). However, they warned that these results measured by BGA must be validated by core LA. Similarly, in another study conducted by Budak et al. (11), the agreement limit for $\mathrm{K}^{+}$was found as -0.5 to 1.1 , and authors concluded that $\mathrm{K}^{+}$results obtained using BGA and LAA cannot be interchangeable in clinical practice (11). In contrast, although Zhang et al. (12) in their study found similar agreement limits for $\mathrm{K}^{+}$measurements as -0.29 to 1.16 , they concluded that $\mathrm{K}^{+}$ results measured by BGA are reliable. We believe that these different perspectives can cause that optimal agreement limits are subjective and can change in different clinical scenarios. However, we think that at least if $\mathrm{K}^{+}$results of $\mathrm{BGA}$ are in normal range, it can be reliable for exclusion of mortal hyperkalemia or hypokalemia with these agreement limits. Thus, we believe that $\mathrm{K}^{+}$measurements by BGA can be helpful in the management of patients in the ED practice.

Hgb and Htc measurements

In patients with hemorrhage (traumatic or non-traumatic), early evaluation of $\mathrm{Hgb}$ and Htc levels is crucial because the current guidelines stated that detected low initial $\mathrm{Hgb} / \mathrm{Htc}$ values could be an indicator for severe bleeding (13). Therefore, at the beginning of our study, we thought that measurements of $\mathrm{Hgb}$ and $\mathrm{Htc}$ values by BGA could be useful for the assessment of the hemorrhagic stage in the early period of trauma management in the ED. However, in the present study, we found that there are no strong correlation and unacceptable agreement limits for $\mathrm{Hgb}$ and $\mathrm{Htc}$ measurements in the clinical ED practice. Similar to our results, in their study, Uysal et al. (5) found wide unacceptable agreement limits for Hgb and Htc measurements by BGA and LAA (mean diff. of Hgb: -0.03 , LoA: -2.23 to 1.71 and mean diff. of Htc: -2.19 , LoA: -8.75 to 4.36 ). Similarly, in another study conducted by Kozaci et al. (14) with 100 patients' laboratory results, some laboratory results, including $\mathrm{Hgb}$ and Htc measured by BGA and standard automatic devices in the core laboratory, were compared. Although they reported that there are high correlations between measurements by BGA and core laboratory analyzer for $\mathrm{Hgb}$ and Htc measurements, agreement limits for $\mathrm{Hgb}$ and $\mathrm{Htc}$ values are mean diff: -0.1, LoA -4.2 to 3.9 and mean diff: -1.5, LoA: -13.9, respectively (14). Moreover, although they concluded that BGA measurements for $\mathrm{Hgb}$ and $\mathrm{Htc}$ values can facilitate the management of patients with active bleeding based on high correlation in their results, we believe that the agreement limits in their study were very wide for use in the clinical practice in the ED, similar to our results. In contrast to the findings of these studies, in the study by Zhang et al. (12), narrower agreement limits for Hgb measurements were reported as mean diff: 0.1, LoA: -1.8 to 1.9 , and they concluded that $\mathrm{Hgb}$ values measured by BGA are reliable. Consequently, despite the presence of different results and opinions in the literature, we think that especially initial $\mathrm{Hgb}$ and $\mathrm{Htc}$ values measured by BGA were not reliable in the management of patients with hemorrhage. However, when we consider that there is 
a relatively high ( $r=0.78$ and 0.79 ) correlation between BGA and LAA for $\mathrm{Hgb}$ and $\mathrm{Htc}$ measurements, serial measurements of $\mathrm{Hgb}$ and Htc by BGA could be useful and helpful for the prediction of severe bleeding.

\section{Study limitations}

There were three important limitations in the present study. First, since all data were analyzed retrospectively, standardization of obtaining VBG may not have been adequate enough. Similarly, although calibration of these BGA devices was performed daily in routine practice, daily calibration standardization may not have been adequate enough. In addition, our study groups were heterogeneous and consisted of various disease groups (medical and trauma). However, we believe that the results with these limitations may be more compatible with real-life scenarios. Second, we analyzed only venous blood samples and not arterial samples. Finally, we did not analyze the triglyceride and total protein levels of the patients. Owing to using indirect ISE in $\mathrm{Na}^{+}$and $\mathrm{K}^{+}$measurements, we could not evaluate the potential effect of triglyceride and total protein levels on measurements of $\mathrm{Na}^{+}$and $\mathrm{K}^{+}$. If the present study did not have these limitations, more appropriate results might have been found.

\section{Conclusion}

In conclusion, our results showed that there is a strong correlation between measurements by BGA and LAA for $\mathrm{K}^{+}$values; however, there is no strong correlation for $\mathrm{Na}^{+}, \mathrm{Hgb}$, and $\mathrm{Htc}$ values. In addition, when considering the agreement limits, although relatively good acceptable agreement limits were found for $\mathrm{K}^{+}$values, agreement limits of $\mathrm{Na}^{+}, \mathrm{Hgb}$, and $\mathrm{Htc}$ values were found as unacceptable for use in the clinical ED practice.

Ethics Committee Approval: Ethics committee approval was received for this study from the Ethics Committee of Health Sciences Unviersity Kecioren Training and Research Hospital (Protocol ID: 102016/1222-Number: 2012KAEK-15/1222).

Informed Consent: Informed consent was not taken from patients due to the retrospective nature of the study.

Peer-review: Externally peer-reviewed.

Author Contributions: Concept - S.K.C., E.E., Y.C.; Design - S.K.C., E.E., S.D.; Supervision - S.K.C., E.E., Y.C., S.D.; Resources - S.K.C., Y.C.; Data Collection and/ or Processing - M.A.O., S.A., H.S.C.; Analysis and/or Interpretation - S.D., S.K.C., E.E.; Literature Search - M.A.O., S.A., H.S.C.; Writing Manuscript - E.E., S.K.C.; Critical Review - Y.C., E.E., S.A.

Conflict of Interest: The authors have no conflict of interest to declare.
Financial Disclosure: The authors declared that this study has received no financial support.

\section{References}

1. Price CP. Medical and economic outcomes of point-of-care testing. Clin Chem Lab Med. 2002; 40: 246-51. [CrossRef]

2. Rahim-Taleghani S, Fatemi A, Alavi Moghaddam M, Shojaee M, Abushouk $\mathrm{Al}$, Forouzanfar MM, et al. Correlation of central venous pressure with venous blood gas analysis parameters; a diagnostic study. Turk J Emerg Med. 2016; 17: 7-11. [CrossRef]

3. The United States Clinical Laboratory Improvement Amendments (CLIA). Regulations and Federal Register Documents. Standards and Certification: Laboratory Requirements (42 CFR 493). CLIA Code of Federal Regulations. Subpart I Proficiency Testing Programs by Specialty and Subspecialty. 493.931 Routine chemistry. Available from: URL: https://www.law.cornell.edu/cfr/text/42/493.931.

4. Jain A, Subhan I, Joshi M. Comparison of the point-of-care blood gas analyzer versus the laboratory auto-analyzer for the measurement of electrolytes. Int J Emerg Med. 2009; 2: 117-20. [CrossRef]

5. Uysal E, Acar YA, Kutur A, Cevik E, Salman N, Tezel O. How reliable are electrolyte and metabolite results measured by a blood gas analyzer in the ED? Am J Emerg Med. 2016; 34: 419-24. [CrossRef]

6. Uyanik M, Sertoglu E, Kayadibi H, Tapan S, Serdar MA, Bilgi C, et al. Comparison of blood gas, electrolyte and metabolite results measured with two different blood gas analyzers and a core laboratory analyzer. Scand J Clin Lab Invest. 2015; 75: 97-105. [CrossRef]

7. Leino A, Kurvinen K. Interchangeability of blood gas, electrolyte and metabolite results measured with point-of-care, blood gas and core laboratory analyzers. Clin Chem Lab Med. 2011; 49: 1187-91. [CrossRef]

8. Braun MM, Barstow $\mathrm{CH}$, Pyzocha NJ. Diagnosis and management of sodium disorders: hyponatremia and hypernatremia. Am Fam Physician. 2015; 91: 299-307.

9. Rossignol $P$, Legrand $M$, Kosiborod $M$, Hollenberg $S M$, Peacock WF, Emmett $M$, et al. Emergency management of severe hyperkalemia: Guideline for best practice and opportunities for the future. Pharmacol Res. 2016; 113: 585-91. [CrossRef]

10. Solak Y. Comparison of serum sodium levels measured by blood gas analyzer and biochemistry autoanalyzer in patients with hyponatremia, eunatremia, and hypernatremia. Am J Emerg Med. 2016; 34: 1473-9. [CrossRef]

11. Budak YU, Huysal K, Polat M. Use of a blood gas analyzer and a laboratory autoanalyzer in routine practice to measure electrolytes in intensive care unit patients. BMC Anesthesiol. 2012; 12: 17. [CrossRef]

12. Zhang JB, Lin J, Zhao XD. Analysis of bias in measurements of potassium, sodium and hemoglobin by an emergency department-based blood gas analyzer relative to hospital laboratory autoanalyzer results. PLoS One. 2015; 10: e0122383. [CrossRef]

13. Rossaint R, Bouillon B, Cerny V, Coats TJ, Duranteau J, FernándezMondéjar $E$, et al. The European guideline on management of major bleeding and coagulopathy following trauma: fourth edition. Crit Care. 2016; 12; 20: 100.

14. Kozaci N, MO Ay, Guven R, Sasmaz I, Karaca A. Comparison of $\mathrm{Na}, \mathrm{K}, \mathrm{Cl}$, $\mathrm{Hb}$ and $\mathrm{Hct}$ values measured by blood gas analyzer and laboratory autoanalyzer. Turk Biyokim Derg. 40: 343-7. 